\title{
Changes in the Localization of Perforated Peptic Ulcer and its Relation to Gender and Age of the Patients throughout the Last 45 Years
}

\author{
Andrzej Wysocki • Piotr Budzyński • \\ Jan Kulawik • Włodzimierz Drożdż
}

Published online: 26 January 2011

(c) The Author(s) 2011. This article is published with open access at Springerlink.com

\begin{abstract}
Background Throughout recent decades there has been noticeable change in the incidence of peptic ulcer disease and its complications. The aim of the present study was to determine the character of changes over the last 45 years in the localization of perforation, in patient age, and in patient gender.

Methods A group of 881 patients admitted to the Second Department of General Surgery in Krakow, Poland, from 1962 to 2006 were included in the study and constituted the material for the analysis. The study was divided into three time periods (1962-1976, 1977-1991, and 1992-2006) to allow statistical analysis of trends.

Results The general incidence of perforations of peptic ulcer did not show changes; however, the percentage of women with perforated duodenal ulcer markedly increased. Patients with perforated stomach ulcer-regardless of gender-and females suffering from perforated duodenal ulcer were, on the average, about 10 years older than males with perforated duodenal ulcers. The mean age of male and female patients with perforated duodenal ulcer over the last 45 years showed an insignificant upward trend.

Conclusions (1) The percentage of women with perforated duodenal ulcer continuously and statistically significantly rose. (2) Men with perforated duodenal ulcer were significantly younger than other patients. (3) The mean ages of male and female patients with perforated duodenal ulcer over the last 45 years showed an insignificant upward trend.
\end{abstract}

A. Wysocki · P. Budzyński ( $₫) \cdot J$. Kulawik · W. Drożdż Faculty of Medicine, Second Department of General Surgery, Jagiellonian University Medical College, Kopernika 21, 31-501 Krakow, Poland

e-mail: budzynp@cm-uj.krakow.pl

\section{Introduction}

Epidemiological research on uncomplicated peptic ulcer disease is methodically difficult and thus not free from mistakes. One of the causes of such a situation is a diverse clinical course of peptic ulcer disease, with mutable intensity of complaints and the presence of interweaving periods of relapse and remissions of different duration. Another problem results from changes in the diagnostic workup confirming peptic ulcer that evolved from clinical assessment alone, through radiological examination, to gastroscopy, which nowadays constitutes the diagnostic method of choice. Altogether, these are the reasons for difficulty in comparing the present incidence of the disease with the morbidity recorded in the past. Another problem affecting the precision of epidemiological research is the presence of still-improving pharmaceutical agents that have led to a marked decrease in the number of patients hospitalized for the treatment of peptic ulcer. Moreover, there is still a large group of young patients being treated only on the basis of clinical assessment, without gastroscopy confirming the ulcer and its location [1-6].

The situation is different in cases of complications of peptic ulcer disease that usually cause severe complaints and constitute an indication for hospitalization. Similarly, in cases of bleeding ulcer and stenosis of the gastric outlet, the complaints usually lead to hospitalization. Nevertheless, both diagnostic and therapeutic approaches have changed so much during the last half century that present observations cannot be compared with previous ones.

Perforation of peptic ulcer constitutes a unique situation characterized by severe pain, leading almost every patient with this complication to seek help in the hospital. On the basis of criteria that have remained invariable for decades, such patients are, as a rule, treated surgically, and that not 
only allows for verification of the diagnosis but also for the precise localization of the ulcer as well, thus making possible comparison of data collected over many years.

Determination of changes in the localization of perforated peptic ulcer and variations in gender and age of the patients over the last 45 years constituted the aim of the present study.

\section{Materials and methods}

Between 1 January 1962 and 31 December 2006, 871 patients underwent operation for perforated peptic ulcer in the Second Department of General Surgery of Jagiellonian University Medical College in Krakow. In another ten patients admitted in a terminal state, the diagnosis of perforation was made at autopsy. In the whole group of 881 patients included in the study, there were 776 cases of perforated duodenal ulcer and 105 cases of perforated stomach ulcer. There were 672 male and 209 female patients.

Our referral population was not demographically constant for the whole 45 years of the study period. However, with the increase in the head count of the population of Krakow came the foundation of new hospitals admitting acute surgical cases in the same area. Thus the number of patients with acute surgical diseases treated in the Second Department of General Surgery of Jagiellonian University Medical College in Krakow remained on comparable level until 2002. Differences in the incidence of gastric ulcer calculated for this population did not differ significantly. In women the incidence increased from 0.8 to $1.2 / 100,000 /$ year, whereas, in men, the incidence decreased from 3.4 to 2.3. Simultaneously the incidence of duodenal ulcer in the male population decreased from 29.6 to 22.7 (difference insignificant statistically), whereas in the female population it increased significantly from 3.5 to 9.4. Unfortunately, because of some more pronounced changes in the referral population and the structure of the medical service from 2003 to the present, we were not able to calculate the exact incidence and present it in our study. The observation time of 45 years was divided into three periods: 1962-1976 (15 years), 1977-1991 (15 years), and 1992-2006 (15 years). Calculations were made separately for each gender and for stomach ulcers and duodenal ulcers. Student's $t$ test and the $\chi^{2}$ test were used in statistical assessment.

\section{Results}

Localization

Throughout the 45-year observation time, perforation of duodenal ulcer proved to be more than seven times more frequent than perforation of stomach ulcer when calculated together for both sexes. Differences among particular periods of the study were slight and did not show statistical significance (Table 1).

\section{Gender}

There was an increase in the percentage of women in the group of patients with perforated duodenal ulcer observed in consecutive periods of the study (Table 2). Differences in the proportion of female patients between the third and the second periods and between the third and the first periods were statistically significant $(P<0.01)$. An increase in the percentage of women between the first and the second periods also proved significant $(P<0.05)$.

There were no statistically significant differences observed in gender distribution of perforated gastric ulcer (Table 3).

Table 1 Localization of perforated peptic ulcer

\begin{tabular}{llcl}
\hline Period & $\begin{array}{l}\text { Duodenal } \\
\text { ulcer } n(\%)\end{array}$ & $\begin{array}{l}\text { Stomach } \\
\text { ulcer } n(\%)\end{array}$ & $\begin{array}{l}\text { Together } \\
n\end{array}$ \\
\hline I (1962-1976) & $227(87.6)$ & $21(12.4)^{\mathrm{a}}$ & 259 \\
II (1977-1991) & $249(86.5)$ & $39(13.5)^{\mathrm{b}}$ & 288 \\
III (1992-2006) & $300(89.8)$ & $34(10.2)^{\mathrm{c}}$ & 334 \\
I + II + III & $776(88.1)$ & $105(11.9)$ & 881 \\
\hline
\end{tabular}

$a / b, a / c$, and $b / c$ differences without statistical significance

Table 2 Gender differences in perforated duodenal ulcer

\begin{tabular}{llcl}
\hline Period & $\begin{array}{l}\text { Male } \\
\text { patients } n(\%)\end{array}$ & $\begin{array}{l}\text { Female } \\
\text { patients } n(\%)\end{array}$ & $\begin{array}{l}\text { Together } \\
n\end{array}$ \\
\hline I (1962-1976) & $199(87.7)$ & $28(12.3)^{\mathrm{a}}$ & 227 \\
II (1977-1991) & $200(80.3)$ & $49(19.7)^{\mathrm{b}}$ & 249 \\
III (1992-2006) & $203(67.7)$ & $97(32.3)^{\mathrm{c}}$ & 300 \\
I + II + III & $602(77.6)$ & $174(22.4)$ & 776 \\
\hline
\end{tabular}

$a / b$ difference with statistical significance $(P<0.05)$

$a / c$ and $b / c$ differences with statistical significance $(P<0.01)$

Table 3 Gender differences in perforated stomach ulcer

\begin{tabular}{lllc}
\hline Period & $\begin{array}{l}\text { Male } \\
\text { patients } n(\%)\end{array}$ & $\begin{array}{l}\text { Female } \\
\text { patients } n(\%)\end{array}$ & $\begin{array}{l}\text { Together } \\
n\end{array}$ \\
\hline I (1962-1976) & $21(65.6)$ & $11(34.4)^{\mathrm{a}}$ & 32 \\
II (1977-1991) & $27(69.2)$ & $12(30.8)^{\mathrm{b}}$ & 39 \\
III (1992-2006) & $22(64.7)$ & $12(35.3)^{\mathrm{c}}$ & 34 \\
I + II + III & $70(66.7)$ & $35(33.3)$ & 105 \\
\hline
\end{tabular}

$a / b, a / c$, and $b / c$ differences without statistical significance 
Age

Mean ages of both male and female patients with perforated duodenal ulcer presented an upward trend; however, that trend was without statistical significance (Tables 4, 5). The mean age of the female patients in every period of the study (a/d, b/e, c/f and for the study as a whole) was significantly higher than mean age of the male patients at $P<0.001$. Mean ages for both sexes showed an upward trend; however, this regularity did not prove to be statistically significant.

Only the mean age of women with perforated stomach ulcer in the third period $(\mathrm{a} / \mathrm{b}$ in Table 5$)$ was significantly higher than in the second period $(P<0.05)$. Otherwise, changes in the age of male and female patients did not show statistical significance. Mean age of female patients-except for the second period-was insignificantly higher than the mean age of male patients, although the mean age of men showed an upward trend.

Men with perforated stomach ulcer were significantly older than men with duodenal ulcer at $P<0.05$ for the first and the third periods, and at $P<0.001$ for the second period. Women with perforated stomach ulcer were only 2 years older than women with duodenal ulcer, and this difference showed no significance, either for the whole group or for particular periods.

For whole study period women with perforated duodenal ulcer were more than 12 years older than men $(P<0.001)$. Mean ages of female patients with duodenal and stomach ulcers were similar. The 9-year difference between the groups of male patients with duodenal and

Table 4 Mean age of patients with perforated duodenal ulcer

\begin{tabular}{lcc}
\hline Period & $\begin{array}{l}\text { Male patients age, } \\
\text { years (SD) }\end{array}$ & $\begin{array}{l}\text { Female patients age, } \\
\text { years (SD) }\end{array}$ \\
\hline I (1962-1976) & $44.5(16.4)^{\mathrm{a}}$ & $55.04(13.98)^{\mathrm{d}}$ \\
II (1977-1991) & $45.8(17.1)^{\mathrm{b}}$ & $57.7(20.7)^{\mathrm{e}}$ \\
III (1992-2006) & $47.2(16.2)^{\mathrm{c}}$ & $60.6(18.97)^{\mathrm{f}}$ \\
I + II + III & $45.85(16.6)$ & $58.89(18.8)$ \\
\hline
\end{tabular}

$a / d, b / e, c / f$ and for whole study group differences with statistical significance $(P<0.001)$

Table 5 Mean age of patients with perforated stomach ulcer

\begin{tabular}{lcc}
\hline Period & $\begin{array}{l}\text { Male patients age, } \\
\text { years (SD) }\end{array}$ & $\begin{array}{l}\text { Female patients age, } \\
\text { years (SD) }\end{array}$ \\
\hline I (1962-1976) & $51.1(12.8)$ & $59.5(21.6)$ \\
II (1977-1991) & $57.6(12.7)$ & $54.25(17.05)^{\mathrm{a}}$ \\
III (1992-2006) & $56.95(15.8)^{\mathrm{c}}$ & $69.25(17.9)^{\mathrm{b}}$ \\
I + II + III & $55.47(13.86)$ & $61.06(19.39)$ \\
\hline
\end{tabular}

$a / b$ difference with statistical significance $(P<0.05)$ stomach ulcers proved to be statistically significant $(P<0.01)$. In the group of patients with perforated stomach ulcer, women were more than 6 years older than men, but this difference proved insignificant.

\section{Discussion}

Jan Mikulicz Radecki, professor of surgery at Jagiellonian University at that time, was mentioned in the literature as the first surgeon who had sutured a perforated ulcer [7]. This statement requires correction-in 1885, during the Congress of Naturalists in Magdeburg, Radecki presented the case of a patient he had operated on in Theodor Billroth's department in Vienna. Precise description of the case includes a 7-cm-long subcardial rupture of the gastric wall and not a perforated ulcer. The lecture was published in the same year in a Cracovian paper titled "Przegląd Lekarski" [8]. Ludwik Heuser in Wuppertal and Hastings Gilford in England in 1892 were truly the first surgeons who successfully closed perforated ulcers [9].

Age and gender of the patients and localization of perforation have changed over the years. For example in the middle of the nineteenth century in England perforation in the subcardial region dominated, with young women being the most commonly affected group of patients [10]. In recent years there has been a marked change in the incidence of peptic ulcer disease observed in many countries [5, 6, 11-14]. Starting in the 1980s there has been a marked decrease in the number of hospitalizations due to peptic ulcer disease. This change is related to the introduction of modern pharmacotherapy, initially based on $\mathrm{H}_{2}$-blockers, and later modified (with the use of proton pump inhibitors [PPIs], which were introduced in 1988) and supplemented with the use of eradication of Helicobacter pylori [5, 6, 14-18]. The decrease in hospitalizations was also a result of ambulatory treatment of uncomplicated peptic ulcer disease. However, despite the use of more and more effective drugs, there was not a comparable decrease in the number of complications of this disease $[6,14,16,18,19]$. In fact, the incidence of complications such as hemorrhage and perforation has fluctuated for years, and marked differences were observed among the various countries and time periods reported [11, $13,15,16,20-27]$. Along with the downward trend in perforations observed in Europe, there was marked increase in the number of perforations observed elsewhere-e.g., in Hong-Kong [14, 21, 24, 26, 27]. Even within a single country there were significant differences between regions (even those close to one another) [20]. Causes of such observations cannot be unequivocally explained; however, the literature suggests a role for changes in dietary customs, smoking habits, and a continuing increase in the use of nonsteroidal anti-inflammatory drugs (NSAIDs) [3, 28-31]. 
Differences concern the general incidence of ulcer and its changes in time, gender proportion, localization of the ulcer and, finally, the age of the patients [5, 21, 27, 30, 32-35]. Changes in the number of perforations in consecutive decades can be explained by the fact that cohorts of people born at the beginning of the twentieth century were more likely to suffer from perforation than people born later [36]. This statement is confirmed by the epidemiological observations of the population of Iceland, which represents a closed population that does not undergo marked fluctuations. Those studies confirmed the highest risk of perforation in the group of people born during the first and the second decades of the twentieth century. In Iceland those generations had the highest prevalence of $H$. pylori antibodies [37].

Nowadays perforations of duodenal ulcer are found mostly in men; however, there has been an increase in the proportion of women [13, 15, 17-19, 38]. Such a trend was also observed in the second half of the twentieth century in Norway [36]. In many studies, coming mostly from Great Britain, authors pay attention to the decrease in the number of ulcer perforations with the concomitant increase in the proportion of elderly women suffering from this complication $[15,17,18,26,27,32,33,39$, 40]. Those changes are related to different factors, including among others, dietary habits (difficult to confirm), including alcohol use. Smoking also seems to play an important role as a causative factor [18, 22, 39, 41]. However, the incidence of ulcer perforations is influenced the most by the use of NSAIDs, which increase the risk of perforation 6-8 times $[11,13,22$, $39,41,42]$. The use of NSAIDs among older women is widespread and still rising, confirming strong relationship between the use of NSAIDs and the incidence of complications of peptic ulcer disease [13, 22, 27-29, 43]. Helicobacter pylori infection-so important in the pathogenesis of uncomplicated peptic ulcer disease-did not prove to play an important role in perforations. In some studies the percentage of infected patients in the group suffering from perforation amounted to about 20\% [39]. Other studies, however, found a low percentage of patients infected with $H$. pylori only in the group of people taking NSAIDs, whereas in the remaining patients the incidence of $H$. pylori infection was similar to the group of uncomplicated peptic ulcer disease [44, 45]. The abovementioned epidemiological study from Iceland also indicates the important role of $H$. pylori infection [37]. It seems that marked differences in the percentage of patients with perforated peptic ulcer infected by $H$. pylori can result from the way in which this infection is confirmed [44].

The percentage of women among patients with perforated duodenal ulcer throughout the 45 years of the study increased almost threefold (from 12.3 to $32.3 \%$ ). This observation cannot be explained only by the longer lifespan of women. In our study an average expected lifespan for both gender groups has increased. In Poland, the expected lifespan for men was about 67 years for the first study period and reached 71 for the last (almost $6 \%$ increase). In the group of Polish women, mean lifespan also increasedfrom almost 75 years for the first study period to almost 80 years for the last one (about a $6 \%$ increase). Differences in lifespan between men and women did not, however, prove significant. Therefore the increasing prevalence of ulcer disease in elderly women does not reflect the longer lifespan of women.

For almost half a century there was an increase in the proportion of women with perforated duodenal ulcer observed in our study. Thus for such localization of perforation, the male to female ratio changed from about $7: 1$ to slightly more than $2: 1$. Similar observations were also found in other studies [6, 15, 19], but still others did not reveal such results $[13,17,18]$.

According to our data, the mean age of women with perforated stomach ulcer did not differ significantly from women with perforation of duodenal ulcer. Their mean age was also similar to the mean age of male patients with perforated stomach ulcer. Only men with perforated duodenal ulcer presented with significantly lower mean age as compared to the above mentioned groups. Similar differences were observed in the study from England that found the mean age of women with perforated duodenal ulcer to be 10 years higher than the mean age of men [15]. However, that study presented a markedly older population than ours, with the mean age of male patients of 67.6 years and that of female patients of 77.6 years [39]. Most of the recent studies revealed a marked increase in the mean age of patients admitted to the hospital for complications of peptic ulcer disease, including perforations [5, 15, 17-19]. Similar results, although without statistical significance, were found in our material.

The introduction of more and more potent anti-ulcer drugs, including eradication of $H$. pylori, proved effective enough to decrease the number of patients hospitalized and treated for uncomplicated peptic ulcer disease. At present, only patients presenting with complications are treated surgically [1, 30, 32, 46, 47]. It is, however, believed that-in the general population-modern treatment of peptic ulcer disease did not cause the significant decrease in the number of complications [34, 46, 47]. Such a statement can, however, be revised, because recent studies from Spain, Sweden, Italy, and Taiwan indicate that from the time of introduction of PPIs the number of perforations markedly decreased [6, 16, 18, 25].

In summary, it is possible to state that divergence between results of the studies on the incidence, characteristics of patients, and localization of perforated ulcer are related to the multifactorial pathogenesis of this 
complication of peptic disease, including regional differences of dietary customs, smoking habits, and prevalence of the use of NSAIDs.

\section{Conclusions}

The percentage of women with perforated duodenal ulcer continuously and statistically significantly rises. Men with perforated duodenal ulcer were significantly younger than women with this complication and than patients with perforated stomach ulcer regardless of gender. Mean ages of male and female patients with perforated duodenal ulcer over the last 45 years showed an insignificant upward trend.

Open Access This article is distributed under the terms of the Creative Commons Attribution Noncommercial License which permits any noncommercial use, distribution, and reproduction in any medium, provided the original author(s) and source are credited.

\section{References}

1. Bardhan KD, Cust G, Hinchliffe RF et al (1989) Changing pattern of admissions and operations for duodenal ulcer. $\mathrm{Br} \mathrm{J}$ Surg 76:230-236

2. Johnsen R, Straume B, Forde OH et al (1992) Changing incidence of peptic ulcer-facts or artefacts? A cohort study from Tromso. J Epidemiol Community Health 46:433-436

3. Rosenstock S, Jorgensen T, Bonnevie O et al (2003) Risk factors for peptic ulcer disease: a population based prospective cohort study comprising 2,416 Danish adults. Gut 52:186-193

4. Schoon IM, Mellstrom D, Oden A et al (1989) Incidence of peptic ulcer disease in Gothenburg, 1985. BMJ 299(6708):1131-1134

5. Wang YR, Richter JE, Dempsey DT (2010) Trends and outcomes of hospitalizations for peptic ulcer disease in the United States, 1993 to 2006. Ann Surg 251:51-58

6. Wu CY, Wu CH, Wu MS et al (2009) A nationwide populationbased cohort study shows reduced hospitalization for peptic ulcer disease associated with $H$. pylori eradication and proton pump inhibitor use. Clin Gastroenterol Hepatol 7:427-431

7. Jennings D (1940) Perforated peptic ulcer: changes in age-incidence and sex-distribution in the last 150 years. Lancet 1:444-447

8. Mikulicz J (1885) O laparotomii w przypadkach przedziurawienia żołądka i jelita. Przegl. Lek XXIV(2):1-3

9. Lau WY, Leow CK (1997) History of perforated duodenal and gastric ulcers. World J Surg 21:890-896

10. Crisp E (1843) Cases of perforation of the stomach with deductions there from relative to the character and treatment of that lesion. Lancet 2:639

11. Lanas A, Garcia-Rodriguez LA, Polo-Tomas M et al (2009) Time trends and impact of upper and lower gastrointestinal bleeding and perforation in clinical practice. Am J Gastroenterol 104:1633-1641

12. Lassen A, Hallas J, de Schaffalitzky Muckadell OB (2006) Complicated and uncomplicated peptic ulcers in a Danish county 1993-2002: a population-based cohort study. Am J Gastroenterol 101:945-953

13. Lohsiriwat V, Prapasrivorakul S, Lohsiriwat D (2009) Perforated peptic ulcer: clinical presentation, surgical outcomes, and the accuracy of the Boey scoring system in predicting postoperative morbidity and mortality. World J Surg 33:80-85
14. Bertleff MJ, Halm JA, Bemelman WA et al (2009) Randomized clinical trial of laparoscopic versus open repair of the perforated peptic ulcer: the LAMA trial. World J Surg 33:1368-1373

15. Bardhan KD, Royston C (2008) Time, change and peptic ulcer disease in Rotherham, UK. Dig Liver Dis 40:540-546

16. Russo P, Brutti C (2007) Proton pump inhibitors and hospital discharge rates for gastrointestinal events in Italy: a national ecological study. Clin Ther 29:751-758

17. Kang JY, Elders A, Majeed A et al (2006) Recent trends in hospital admissions and mortality rates for peptic ulcer in Scotland 1982-2002. Aliment Pharmacol Ther 24:65-79

18. Hermansson M, Ekedahl A, Ranstam J et al (2009) Decreasing incidence of peptic ulcer complications after the introduction of the proton pump inhibitors, a study of the Swedish population from 1974-2002. BMC Gastroenterol 9:25

19. Janik J, Chwirot $P$ (2000) Perforated peptic ulcer-time trends and patterns over 20 years. Med Sci Monit 6:369-372

20. Brown RC, Langman MJ, Lambert PM (1976) Hospital admissions for peptic ulcer during 1958-72. BMJ 1(6000):35-37

21. Koo J, Ngan YK, Lam SK (1983) Trends in hospital admission, perforation and mortality of peptic ulcer in Hong Kong from 1970 to 1980 . Gastroenterology 84:1558-1562

22. Kopelman D (2009) Perforated peptic ulcer: "developing" world versus "developed" world. World J Surg 33:86-87

23. Lazarus S (1964) Perforated peptic ulcer in Israel. Gut 5:590-596

24. Mackay C, Mackay HP (1976) Proceedings: perforated peptic ulcer in the west of Scotland 1964-73. Br J Surg 63:157-158

25. Sanchez-Bueno F, Marin P, Rios A et al (2001) Has the incidence of perforated peptic ulcer decreased over the last decade? Dig Surg 18:444-447 discussion 447-448

26. Sanders R (1967) Incidence of perforated duodenal and gastric ulcer in Oxford. Gut 8:58-63

27. Watkins RM, Dennison AR, Collin J (1984) What has happened to perforated peptic ulcer? Br J Surg 71:774-776

28. Armstrong CP, Blower AL (1987) Non-steroidal anti-inflammatory drugs and life threatening complications of peptic ulceration. Gut 28:527-532

29. Collier DS, Pain JA (1985) Non-steroidal anti-inflammatory drugs and peptic ulcer perforation. Gut 26:359-363

30. Gustavsson S, Kelly KA, Melton LJ 3rd et al (1988) Trends in peptic ulcer surgery. A population-based study in Rochester, Minnesota, 1956-1985. Gastroenterology 94:688-694

31. Kato I, Nomura AM, Stemmermann GN et al (1992) A prospective study of gastric and duodenal ulcer and its relation to smoking, alcohol, and diet. Am J Epidemiol 135:521-530

32. Jibril JA, Redpath A, Macintyre IM (1994) Changing pattern of admission and operation for duodenal ulcer in Scotland. Br J Surg 81:87-89

33. MacKay C (1966) Perforated peptic ulcer in the west of Scotland: a survey of 5,343 cases during 1954-63. Br Med J 1(5489):701705

34. McKay AJ, McArdle CS (1982) Cimetidine and perforated peptic ulcer. Br J Surg 69:319-320

35. Valerio D, Hendry W, Kyle G (1982) Gastroduodenal perforation in North East Scotland, 1972-1981; a rise in incidence. Gut 23:38-39

36. Svanes C (2000) Trends in perforated peptic ulcer: incidence, etiology, treatment, and prognosis. World J Surg 24:277-283

37. Thors H, Svanes C, Thjodleifsson B (2002) Trends in peptic ulcer morbidity and mortality in Iceland. J Clin Epidemiol 55:681-686

38. Svanes C, Salvesen H, Stangeland L et al (1993) Perforated peptic ulcer over 56 years. Time trends in patients and disease characteristics. Gut 34:1666-1671

39. Canoy DS, Hart AR, Todd CJ (2002) Epidemiology of duodenal ulcer perforation: a study on hospital admissions in Norfolk, United Kingdom. Dig Liver Dis 34:322-327 
40. Negre J (1985) Perforated ulcer in elderly people. Lancet 2(8464):1118-1119

41. Svanes C, Soreide JA, Skarstein A et al (1997) Smoking and ulcer perforation. Gut 41:177-180

42. Garcia Rodriguez LA, Jick H (1994) Risk of upper gastrointestinal bleeding and perforation associated with individual nonsteroidal anti-inflammatory drugs. Lancet 343(8900):769-772

43. Coggon D, Lambert P, Langman MJ (1981) 20 years of hospital admissions for peptic ulcer in England and Wales. Lancet 1(8233):1302-1304

44. Gisbert JP, Pajares JM (2003) Helicobacter pylori infection and perforated peptic ulcer prevalence of the infection and role of antimicrobial treatment. Helicobacter 8:159-167
45. Ng EK, Chung SC, Sung JJ et al (1996) High prevalence of Helicobacter pylori infection in duodenal ulcer perforations not caused by non-steroidal anti-inflammatory drugs. Br J Surg 83:1779-1781

46. Christensen A, Bousfield R, Christiansen J (1988) Incidence of perforated and bleeding peptic ulcers before and after the introduction of H2-receptor antagonists. Ann Surg 207:4-6

47. Paimela H, Tuompo PK, Perakyl T et al (1991) Peptic ulcer surgery during the $\mathrm{H} 2$-receptor antagonist era: a population-based epidemiological study of ulcer surgery in Helsinki from 1972 to 1987. Br J Surg 78:28-31 